\title{
Thermodynamic Modelling of Supersonic Gas Ejector with Droplets
}

\author{
Sergio Croquer ${ }^{1}$, Sébastien Poncet ${ }^{1, *(1)}$ and Zine Aidoun ${ }^{2}$ \\ 1 Department of Mechanical Engineering, Université de Sherbrooke, Sherbrooke, QC J1K 2R1, Canada; \\ sergio.croquer.perez@USherbrooke.ca \\ 2 Natural Resources Canada, CanmetEnergy, Varennes, QC J3X 1P7, Canada; zine.aidoun@canada.ca \\ * Correspondence: sebastien.poncet@USherbrooke.ca; Tel.: +1-819-821-8000 (ext. 62150)
}

Received: 21 September 2017; Accepted: 24 October 2017; Published: 30 October 2017

\begin{abstract}
This study presents a thermodynamic model for determining the entrainment ratio and double choke limiting pressure of supersonic ejectors within the context of heat driven refrigeration cycles, with and without droplet injection, at the constant area section of the device. Input data include the inlet operating conditions and key geometry parameters (primary throat, mixing section and diffuser outlet diameter), whereas output information includes the ejector entrainment ratio, maximum double choke compression ratio, ejector efficiency, exergy efficiency and exergy destruction index. In single-phase operation, the ejector entrainment ratio and double choke limiting pressure are determined with a mean accuracy of $18 \%$ and $2.5 \%$, respectively. In two-phase operation, the choked mass flow rate across convergent-divergent nozzles is estimated with a deviation of $10 \%$. An analysis on the effect of droplet injection confirms the hypothesis that droplet injection reduces by $8 \%$ the pressure and Mach number jumps associated with shock waves occuring at the end of the constant area section. Nonetheless, other factors such as the mixing of the droplets with the main flow are introduced, resulting in an overall reduction by $11 \%$ of the ejector efficiency and by $15 \%$ of the exergy efficiency.
\end{abstract}

Keywords: supersonic ejector; thermodynamic modelling; refrigeration system; droplet injection; shock attenuation; exergy analysis

\section{Introduction}

The use of supersonic ejectors as an alternative to improve the performance and reduce the environmental impact of refrigeration systems has gained interest in recent years. Depending on the role of the device within the cycle, different configurations with varying performance and complexity have been proposed in the literature [1-3]. An interesting choice is the Heat Driven Refrigeration Cycle (HDRC) shown in Figure 1, where the ejector completely substitutes the compressor. Under this scheme, the bottom loop (streams 1-2-6-7-8) is a refrigeration cycle with the compression work coming from the top loop (1-2-3-4-5). Although of modest performance, HDRCs can be operated by low-cost low-grade energy (e.g., industrial waste reject heat or solar thermal power), rendering a cheaper and less pollutant alternative to the standard vapor compression cycle. Moreover, such cycles can also operate with a new class of environmentally friendly refrigerants, named Hydrofluoroolefins (HFOs), without diminishing too much the performances of the system compared to R134a [4]. HDRC systems with water as working fluid can operate at evaporator temperatures as low as $10^{\circ} \mathrm{C}$ and generator temperatures in the range $90-110^{\circ} \mathrm{C}$, resulting in a Coefficient of Performance (COP, the ratio of cooling load to generator heat input) of 0.45 under laboratory conditions [5] and of 0.245 when powered by solar thermal power [6]. A similar performance (COP of 0.3) can be attained with R134a at even lower temperatures: $3^{\circ} \mathrm{C}$ at the evaporator and $90^{\circ} \mathrm{C}$ at the generator $[7,8]$. 


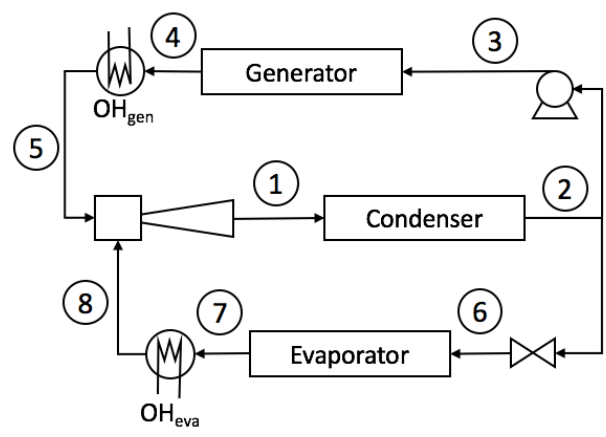

(a)

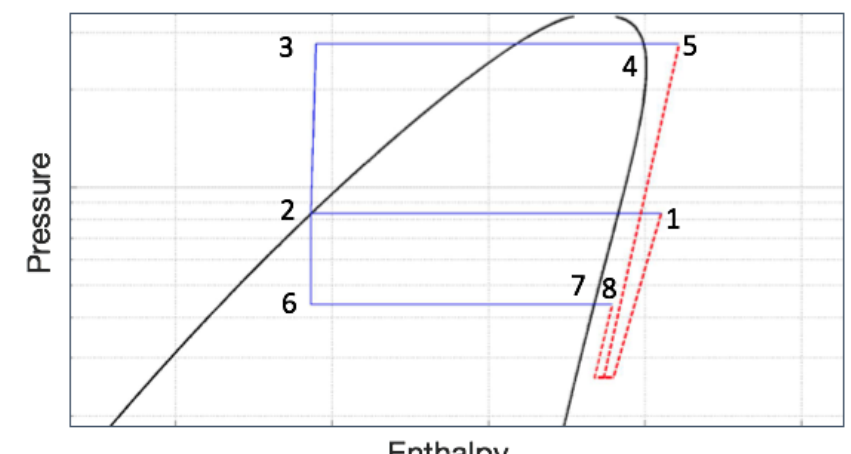

Enthalpy

(b)

Figure 1. (a) Flow process diagram and (b) pressure-enthalpy diagram of a single-phase heat driven refrigeration cycle. The dotted red lines represent the flow inside the ejector.

The heart of these novel refrigeration systems is the supersonic ejector, a simple device where the energy of the motive flow (stream 5 in Figure 1) is used to entrain and compress the secondary flow (stream 8 ). They are known for their simple design, low maintenance requirements and stable operation under single- and two-phase conditions [9]. The typical geometry and main sections of a supersonic ejector assuming a constant area mixing are depicted in Figure 2. Under normal operation, the primary flow (also known as motive flow) is accelerated through the motive nozzle and enters the mixing section as a supersonic jet. At this point, shear interactions develop between both inlet flows until a uniform mixture is formed (position L5). Afterwards, a series of shock waves takes place such that the flow is subsonic at the beginning of the diffuser, where it compresses to outlet conditions.

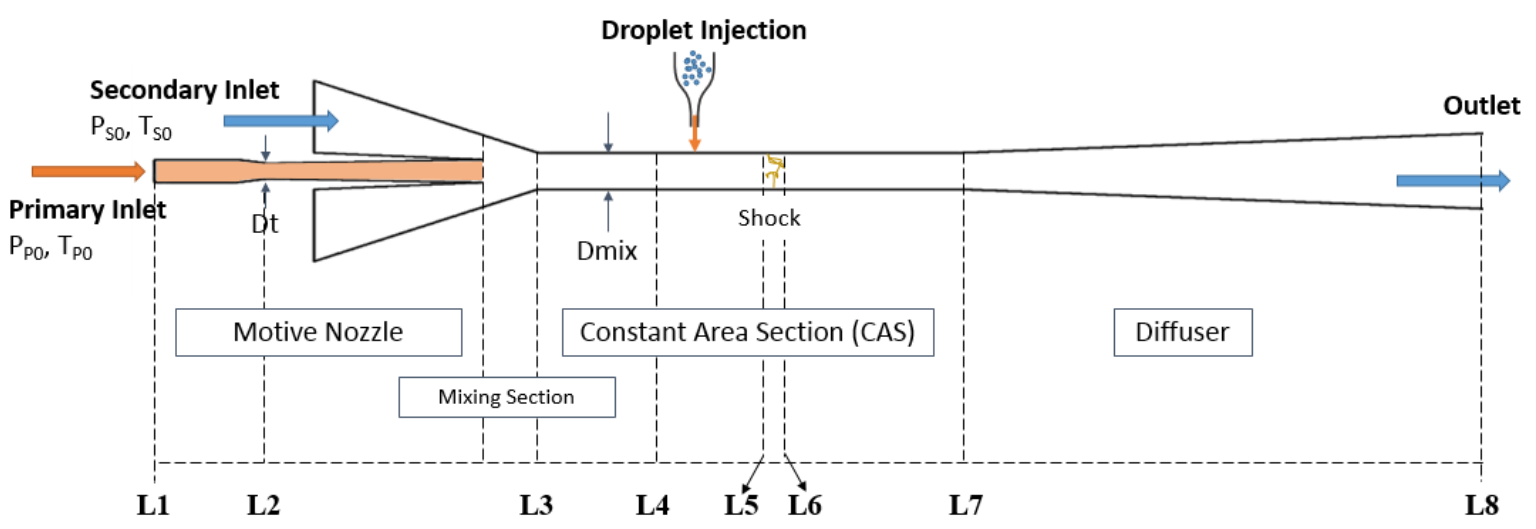

Figure 2. Typical geometry of a constant area ejector.

At fixed inlet conditions, two operating regimes can be recognized depending on the value of the outlet pressure $P_{\text {out }}$ relative to a certain threshold $P_{\text {lim }}$ [10]. For $P_{\text {out }}<P_{\text {lim }}$, the secondary mass flow rate $\dot{m}_{s e c}$ is choked between the primary jet and the outer wall, such that total mass flow rate is at a maximum and independent of the exit pressure. This is known as a double-choke operation. Beyond $P_{\text {lim }}$ the ejector operates under the single-choke regime and $\dot{m}_{s e c}$ decays with increasing $P_{\text {out }}$. At the limit of $\dot{m}_{s e c}=0$, the ejector is said to be in the malfunction regime. The ejector operating range is usually expressed in terms of the entrainment ratio $\left(\omega_{r}\right.$, the ratio of the secondary to primary mass flow rates, Equation (1)) and the pressure ratio ( $P_{\text {ratio }}$, the ratio of the outlet to secondary pressures, Equation (2)). These parameters reflect, respectively, the mass drawing and compression capacity of the device:

$$
\omega_{r}=\frac{\dot{m}_{s e c}}{\dot{m}_{\text {prim }}},
$$




$$
P_{\text {ratio }}=\frac{P_{\text {out }}}{P_{\text {sec }}}
$$

It has been argued that the use of $\omega_{r}$ and $P_{\text {ratio }}$ is limited when the goal is to compare the effectiveness of certain ejector alternatives in the context of a complete system. Therefore, three other parameters have been considered in this study to better reflect these differences: the ejector efficiency $\eta_{\text {Elbel }}$ as proposed by Elbel and Hrnjak [11], which gives insight on the efficiency of the ejector as a compression device; the exergy efficiency $\eta_{\chi}$, which compares the exergy output relative to the sum of the primary and secondary inlets and the ejector efficiency and the exergy destruction coefficient $\xi_{i}$, which reflects the distribution of exergy destruction through the device [12]. These parameters are defined in Section 4.7. The reader is referred to the review of Lawrence and Elbel [13] for a thorough analysis of different ejector performance definitions.

The performance of ejector based refrigeration systems is a direct function of the entrainment ratio [4]. A simple approach to relate cycle operating conditions to the ejector performance is the use of thermodynamic models, which offer a good compromise between accuracy and simplicity. For single-phase ejectors, the entrainment ratio is assumed to be a function of the Effective Area, i.e., the annular passage between the motive jet and the Constant Area Section (CAS) walls where the choking of the secondary flow occurs [14]. The pioneering model applying this concept is the one proposed by Huang et al. [10], which calculates the double-choke entrainment ratio and CAS diameter of gas ejectors, given the inlet operating conditions and motive nozzle dimensions. The model assumes isentropic perfect gas behavior and divides the ejector in key regions: motive nozzle, secondary inlet, mixture before and after the shock and diffuser. Despite its simplicity, it presents an experimental deviation of up to $22.99 \%$ for a vast amount of data concerning a R141b test bench with 11 different motive nozzle designs at varying primary inlet temperatures $\left(78^{\circ} \mathrm{C}\right.$ to $\left.95^{\circ} \mathrm{C}\right)$. It was later extended by Chen et al. [15] to predict the entrainment ratio decay rate under single-choke operation given $P_{\text {lim }}$. Galanis and Sorin [16] proposed to determine the limiting pressure and all the ejector dimensions (given the entrainment ratio) by imposing the positive entropy generation constraint. Their model also introduces the use of polytropic efficiencies instead of the constant isentropic coefficients, which better reflect the pressure ratio variations happening in single-choke operation. The perfect-gas assumption was dropped in the model of Garcia del Valle et al. [17], which used a potential flow solution to determine the secondary flow passage and entrainment ratio of single-phase ejectors. Gas properties were calculated using the Helmholtz equation of state adjusted with experimental data. An average deviation of $7 \%$ relative to the experimental data of Huang et al. [10] was reported, with an important increase in complexity.

For two-phase systems, the applicability of the above mentioned models is limited given the complexity of determining the mixture speed of sound and the possibility of phase-change and metastable states. The former can be avoided by assuming that the choked mass flow per unit area, $G=\rho V$, is a function of the local pressure and inlet conditions [18] (see Section 2.2), whereas the latter brings the need for some assumptions regarding the liquid-vapor interactions. The simplest choice is the Homogeneous Equilibrium Model (HEM), which assumes complete thermodynamic equilibrium between the phases. This model gives accurate results in the region close to and above the critical point [19]. Using this approach, Ameur et al. [20] developed a model for determining the ejector flow properties in the context of Ejector Expansion Refrigeration Cycles, where the primary and secondary flows are, respectively, liquid and vapor and the entrainment ratio is indirectly fixed by the system through the quality at the outlet of the diffuser. Results showed a deviation of $0.21 \%$ to $7.14 \%$ in the choked flow rate prediction for $\mathrm{CO}_{2}$ supersonic nozzles and of $0.63 \%$ to $6.14 \%$ in the compression ratio of a complete ejector when comparing to published experimental data. The reader can refer to the work of He et al. [21] for a more detailed review on the thermodynamic modeling of supersonic ejectors up to 2009 .

To date, the general and internal flow characteristics of ejectors under common operating conditions have been extensively studied using both experimental and numerical approaches. 
The long-term objective being to increase the efficiency of ejector systems, a first attempt is made here to quantify the effect of droplet injection before the onset of the shock train on the performance of ejectors for HDRC applications. The shock train and the mixing process are indeed the two main sources of exery losses within the ejector, being responsible for $40 \%$ of the total exergy losses as shown recently by Croquer et al. [22] for a single-phase supersonic ejector working with R134a. Although it is a common practice in the operation of these cycles to avoid the presence of liquid through the device [8], its effects have not been objectively discussed so far. The presence of droplets might act on two important sources of losses inside the device: the velocity mismatch at the mixing section [23] and the intensity of the shock train in the CAS [22].

In the mixing area, the idea is based on the premise that the high velocity difference between the motive jet and the entrained fluid at the mixing section hinders the entrainment of the secondary fluid [23]. An alternative to reduce the motive flow velocity while maintaining its momentum input is the use of a droplet laden gas. This hypothesis has been tested on an air-driven ejector by augmenting the humidity of the primary inlet flow [23]. Although there were no noticeable effects under double-choke operation, an increase of $13 \%$ to $98 \%$ in the single choke secondary mass flow rate was observed for inlet primary pressures within the range 107 to $446 \mathrm{kPa}$ and inlet humidities between $4.3 \%$ and $11.2 \%$. A similar behavior has been reported along with an increase of $5 \%$ in $P_{\text {lim }}$ for motive inlet humid fractions up to $1 \%$ by Hemidi et al. [24]. Nonetheless, these results should be taken with caution since the ejector was studied as an independent unit in both cases and using an uncommon fluid pair (air-water) in refrigeration systems. For R134a, it has been observed that a reduction in the motive inlet superheat $\left(T_{\text {prim }}-T_{\text {prim }}^{\text {Sat }}\right)$ from $11^{\circ} \mathrm{C}$ to $0{ }^{\circ} \mathrm{C}$ leads to a reduction in $\omega_{r}$ of about $8 \%$, related to greater area occupied by the motive jet in the present of condensation [25]. Although the ejector was a part of a HDRC, no results concerning the system performance or $P_{\text {lim }}$ were provided.

The idea of injecting droplets in the CAS of ejectors sparks from the observation that mists mitigate the propagation and intensity of explosions [26]. Droplets deform and breakup at the encounter with a shock front [27], extracting energy from the gas and reducing its velocity and pressure increase rate [28]. In the context of ejectors, the objective is to reduce the shock intensity in the CAS, which accounts for about $40 \%$ of the exergy destroyed through the device [22].

To this end, this investigation assesses for the first time the potential effects of injecting droplets in the CAS of a supersonic ejector. A thermodynamic model has been developed to determine the entrainment and pressure ratio given the inlet conditions, geometrical parameters (motive throat, CAS and diffuser outlet diameters) and injected droplet fractions. To the best of the authors' knowledge, it has never been considered in the literature. Moreover, the ejector efficiency $\eta_{\text {Elbel }}$ [11], the ejector exergy efficiency $\eta_{\chi}$ and the exergy destruction index $\xi_{i}$ are presented in order to reflect the potential effects over the cycle performance of a HDRC system. The model assumptions, input/output information and fundamental equations are given in Section 2. The droplet breakup energy calculation procedure is described in Section 3. Section 4 depicts the calculation procedure for each section of the ejector as well as the performance parameters. The model is then extensively validated for single- and two-phase operations in Section 5. The effect of droplet injection on the performance of a typical ejector for refrigeration purposes is analyzed in Section 6, followed by concluding remarks in Section 7.

\section{Numerical Modeling}

The thermodynamic model determines the performance of the ejector with and without droplet injection by dividing the device into sections depicted in Figure 2 and solving the mass, momentum and energy conservation equations for each region. The required and resulting information of the model as well as the basic assumptions are described in the following subsections.

\section{Input Data}

- Thermodynamic state at both inlets: $P_{\text {prim }}, T_{\text {prim }}, T_{\text {sec }}$ and $P_{\text {sec }}$.

- Diameters at the primary throat $D_{t}$, constant area section $D_{\text {mix }}$ and the diffuser exit $D_{L 8}$. 
- Loss coefficients for the primary nozzle $\eta_{\text {prim }}$, secondary inlet $\eta_{s e c}$, mixing section $\eta_{\text {mix }}$ and diffuser $\eta_{\text {diff }}$.

- For droplet injection:

- Injected fraction, $X_{i n j}=\dot{m}_{\text {injected droplets }} / \dot{m}_{\text {prim, without injection }}$.

- Droplet injection diameter, $\phi_{i n j}$.

- $\quad$ Temperature of droplets at the injector, $T_{i n j}$.

- Injector diameter, $D_{i n j}$.

Output Data

- Primary $\dot{m}_{\text {prim }}$ and secondary $\dot{m}_{\text {sec }}$ mass flow rates and entrainment ratio.

- $\quad$ Thermodynamic properties at every ejector section $L_{i}$ indicated in Figure 2.

- $\quad$ Limiting pressure, $P_{\text {lim }}$.

- Ejector efficiency, $\eta_{\text {Elbel }}$.

- Exergy efficieny, $\eta_{\chi}$.

Main Assumptions

- Flow is 1D and steady-state and its properties are uniform at each cross section $L_{i}$.

- The secondary flow throat (Effective Area) occurs at position $L 3$.

- The pressure at position $L 3$ maximizes the secondary flow.

- $\quad$ A normal shock occurs before the diffuser inlet, between positions $L 5$ and $L 7$.

- Before the normal shock, both inlet flows and injected droplets are fully mixed.

- Losses are represented using expansion and compression isentropic efficiencies.

Concerning the droplet injection, the following assumptions have been made:

- The chemical component of the droplets is the same as the gas phase used in the primary and secondary inlets.

- The droplets are in complete mechanical and thermal equilibrium with the gas phase $\left(V_{\text {slip }}=0\right)$.

- Droplets are spherical and form a monodisperse phase.

- Droplets are injected between positions $L 4$ and $L 5$, normal to the main flow.

- Droplet breakup occurs right after injection and through the shock waves.

- Coalescence and droplet deformation effects are neglected.

\subsection{General Governing Equations}

For each region, the conservation principles of mass, momentum and energy are applied. In the general case of a control volume with two inlet faces $(i n, 1$ and $i n, 2)$ and one outlet (out), the conservation equations take the following form:

Conservation of mass:

$$
\rho_{\text {in }, 1} V_{\text {in }, 1} A_{\text {in }, 1}+\rho_{\text {in }, 2} V_{\text {in }, 2} A_{\text {in }, 2}=\rho_{\text {out }} V_{\text {out }} A_{\text {out }},
$$

Conservation of momentum:

$$
\left[P_{i n, 1} A_{i n, 1}+\dot{m}_{i n, 1}\right]+\left[P_{i n, 2} A_{i n, 2}+\dot{m}_{i n, 2}\right]=\left[P_{\text {out }} A_{\text {out }}+\dot{m}_{\text {out }}\right],
$$

Conservation of energy:

$$
\dot{m}_{i n, 1}\left[h_{i n, 1}+\frac{1}{2} V_{i n, 1}^{2}\right]+\dot{m}_{i n, 2}\left[h_{i n, 2}+\frac{1}{2} V_{i n, 2}^{2}\right]=\dot{m}_{\text {out }}\left[h_{\text {out }}+\frac{1}{2} V_{\text {out }}^{2}\right],
$$


where $\rho$ is the fluid density, $V$ is the flow velocity, $A$ is the cross sectional area, $P$ is the pressure, $m$ is the mass flow rate and $h$ is the specific enthalpy. Fluid properties are determined using the CoolProp equation library, which relies on the Helmholtz free energy formulation to provide thermodynamic and transport properties within a $1 \%$ accuracy for a wide range of fluids [29]. The library covers conditions up to $30 \mathrm{MPa}$ and $523 \mathrm{~K}$ for $\mathrm{CO}_{2}$ and between $170 \mathrm{~K}$ and $455 \mathrm{~K}$ and up to $70 \mathrm{MPa}$ for R134a.

In two-phase conditions, thermodynamic equilibrium is assumed at each cross section. The model defines any two-phase state by combining the section pressure with either the specific enthalpy $h$ or the specific entropy $s$ and the mixture quality $x_{l}$ :

$$
x_{l}=\frac{\dot{m}_{l}}{\dot{m}_{v}+\dot{m}_{l}}=\frac{b_{m}-b_{l}^{\text {sat }}}{b_{v}^{\text {sat }}-b_{l}^{\text {sat }}}
$$

where $b$ is any thermodynamical property other than $P, T$ or $\rho$. The subscripts $m, l$ and $v$ refer to mixture and saturated liquid and vapor, respectively. The superscript sat refers to saturation conditions (evaluated at the section pressure).

Losses along the expansion (inlets) and compression (diffuser) stages of the ejector are represented using isentropic coefficients $\eta_{\text {expansion }}$ and $\eta_{\text {compression }}$ respectively for each section, whereas a mixing efficiency $\eta_{m i x}$ is introduced to account for friction losses in the mixing chamber [16]:

$$
\begin{aligned}
\eta_{\text {expansion }} & =\frac{h_{\text {in }}-h_{\text {out }}}{h_{\text {in }}-h_{\text {out }}^{\text {is }}}, \\
\eta_{\text {compresion }}= & \frac{h_{\text {out }}^{\text {os }}-h_{\text {in }}}{h_{\text {out }}-h_{\text {in }}}, \\
\eta_{\text {mix }} & =\frac{P_{\text {out }} A_{\text {out }}-P_{\text {in }} A_{\text {in }}+\dot{m}_{\text {out }} V_{\text {out }}}{\dot{m}_{\text {in }} V_{\text {in }}},
\end{aligned}
$$

where the superscript is denotes properties evaluated for an isentropic process between the same start and end points.

\subsection{Calculation of the Entrainment Ratio}

The entrainment ratio is calculated by assuming that the secondary mass flow rate chokes at position $L 3$ through the area available between the primary jet and the CAS walls $\left(A_{L 3, s e c}\right)$ [14]. The choked flow for a given set of inlet conditions is calculated by maximizing the mass flow per unit area, $G$ [30]:

$$
G=\frac{\dot{m}}{A}=V \rho
$$

Such an approach has been also successfully employed by Ameur et al. [20]. It enables to avoid the use of the speed of sound, which remains an open question in the literature when dealing with two-phase flows.

Throughout an isentropic expansion with fixed inlet specific total enthalpy $\left(h_{0}\right)$ and specific total entropy $\left(s_{0}\right)$, the local velocity and density can be expressed in terms of the inlet conditions and the varying local pressure:

$$
\begin{gathered}
\rho=\rho\left(P, s_{0}\right), \\
V=\sqrt{2\left[h_{0}-h\left(P, s_{0}\right)\right]},
\end{gathered}
$$

Such that:

$$
G=G\left(P, h_{0}, s_{0}\right)=\sqrt{2\left[h_{0}-h\left(P, s_{0}\right)\right]} \rho\left(P, s_{0}\right) .
$$

The function $G$ in Equation (11) exhibits a maximum $G^{*}$, which occurs at sonic conditions. In two-phase homogeneous systems, most of the choked conditions locate over the saturation line $[18,20]$. 
The double choke primary and secondary mass flow rates are respectively: $\dot{m}_{\text {prim }}=G_{p r i m}^{*} A_{L 2}$ and $\dot{m}_{s e c}=G_{s e c}^{*} A_{L 3, s e c}$.

\section{Droplets Effects}

Droplets injected into the CAS are expected to affect the main flow by extracting energy for breakup and by altering the main flow thermodynamic properties. It is assumed that breakup may occur at two locations: at the first encounter with the main flow (between locations L4-L5) and through the shock waves before the diffuser ( $L 5-L 7)$. The injected droplets are assumed to become part of the main flow mixture fast enough so there is thermodynamic equilibrium at sections $L 5$ through $L 8$. It alters the thermodynamic properties of the flow relative to the baseline case (without injection). The terms related to the breakup energy of a droplet are described in the following subsection.

\subsection{Breakup Energy}

The surface energy of a droplet can be defined as the product of its surface area $S_{d}$ by its surface tension $\sigma$ [31]. For a spherical droplet of diameter $\phi_{d}$, it is defined as:

$$
E_{s}=S_{d} \sigma=\pi \phi_{d}^{2} \sigma
$$

Figure 3 presents a schematics of the surface energy transition during breakup. The droplet breakup energy $\Delta E_{b r}$ is the difference in surface energy between the mother droplet $E_{s, 1}$ and a daughter $E_{s, 3}$. Hence, for one droplet breaking into $n_{3}$ daughters, the droplet breakup energy writes:

$$
\Delta E_{b r}=\pi \sigma\left(n_{3} \phi_{3}^{2}-\phi_{1}^{2}\right)=\pi \sigma \phi_{1}^{2}\left(\frac{\phi_{1}}{\phi_{3}}-1\right) .
$$

Note that $n_{3}$ has been eliminated from Equation (13) by applying mass conservation. Moreover, since $\phi_{3}<\phi_{1}$, then $\Delta E_{b r}>0$, meaning breakup always extracts energy from the main flow.

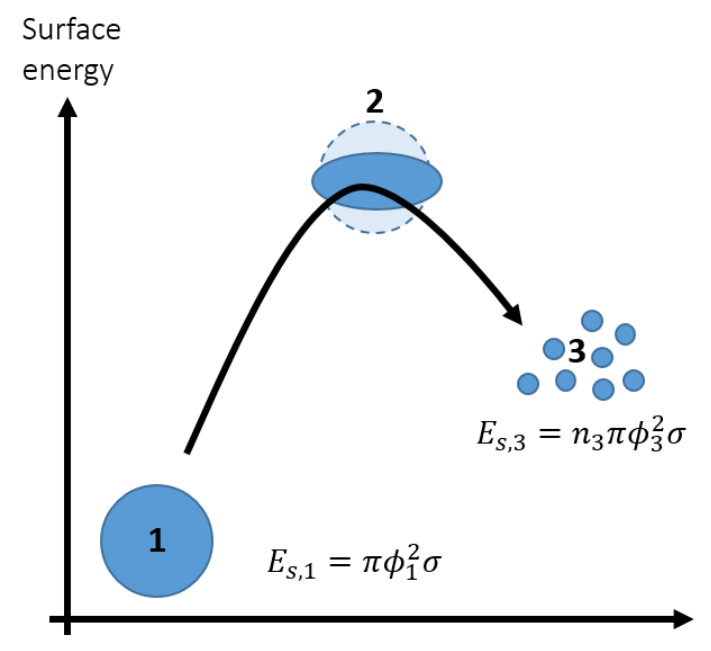

Figure 3. Variation of the droplet surface energy during breakup.

The breakup mechanism and resulting droplet size depend on the counter balance between the surface tension and shear forces exerted by the surrounding gas, represented by the Weber (Equation (14)) number We:

$$
W e=\frac{\rho_{g}^{*} V_{S}^{2} \phi_{d}}{\sigma_{d}}
$$

where $\rho_{g}^{*}$ is the surrounding gas density and $V_{S}$ is the relative velocity, i.e., the difference between the gas phase velocity and the initial velocity of the droplets. This last one being relatively small at the 
injection point, it is assumed that $V_{S}$ is directly the gas phase velocity.

Three different breakup mechanisms can be recognized depending on $W e$ and the droplet Reynolds number $\left(R e_{d}=\frac{\rho_{g}^{*} V_{S} \phi_{d}}{\mu_{g}}\right)$ [27]. In particular, no breakup should be expected for local Weber numbers under a critical value $W e_{c}$, calculated using Equation (15) [32]:

$$
W e_{c}=12\left(1+1.077 O h^{1.6}\right)
$$

where $\mathrm{Oh}$ is the Ohnesorge number, relating the viscous to inertial and surface tension forces in a droplet:

$$
O h=\frac{\sqrt{W e}}{R e_{d}}
$$

Using Equation (15), the final droplet diameter after breakup in Equation (13) is:

$$
\phi_{3}=\frac{\sigma W e_{c}}{\rho_{g} V_{s}^{2}} .
$$

The reader can refer to the review of Liao and Lucas [33] for more details about advanced theoretical models for droplet breakup.

\subsection{Droplet Injection}

At the point of injection, Equations (14)-(17) are used to calculate the daughter droplet size diameter $\phi_{L 5}$. Droplet properties at the point of injection are determined using $P_{L 3}$ and the injection temperature. If the corresponding state is not subcooled liquid, saturated liquid at $P_{\mathrm{L} 3}$ is assumed leading to an injection temperature equal to $T=263 \mathrm{~K}$ here. The droplet injection velocity stems from the injector diameter, the injected droplet fraction $X_{i n j}$ and droplet density $\rho_{i n j}$.

For an injection flow rate $\dot{m}_{i n j}$ of droplets with constant diameter $\phi_{i n j}$, the total breakup energy between sections $L 4$ and $L 5$ is:

$$
\Delta E_{b r, i n j}=\frac{6 \sigma \dot{m}_{i n j}}{\rho_{i n j} \phi_{i n j}}\left(\frac{\phi_{i n j}}{\phi_{L 5}}-1\right) .
$$

For the breakup terms across the shock, the quality of the mixture is determined first at position $L 5$. If $0<x_{L, L 5}<1$, an analogous calculation to that at the injection point is carried out using the liquid mass in the mixture $\left(\dot{m}_{\text {Liquid }}=\dot{m}_{5} x_{L, L 5}\right)$ and the properties at $L 5$ to determine the droplet sizes and total breakup energy $\Delta E_{b r, L 7}$.

\section{Ejector Calculation Procedure}

The following thermodynamic model has been implemented within a Matlab environment. Starting from the primary nozzle, the flow properties at each cross section $L_{i}$ are determined in a advancing fashion following the general procedure shown in Figure 4. Details of the calculations at each section are given below. 


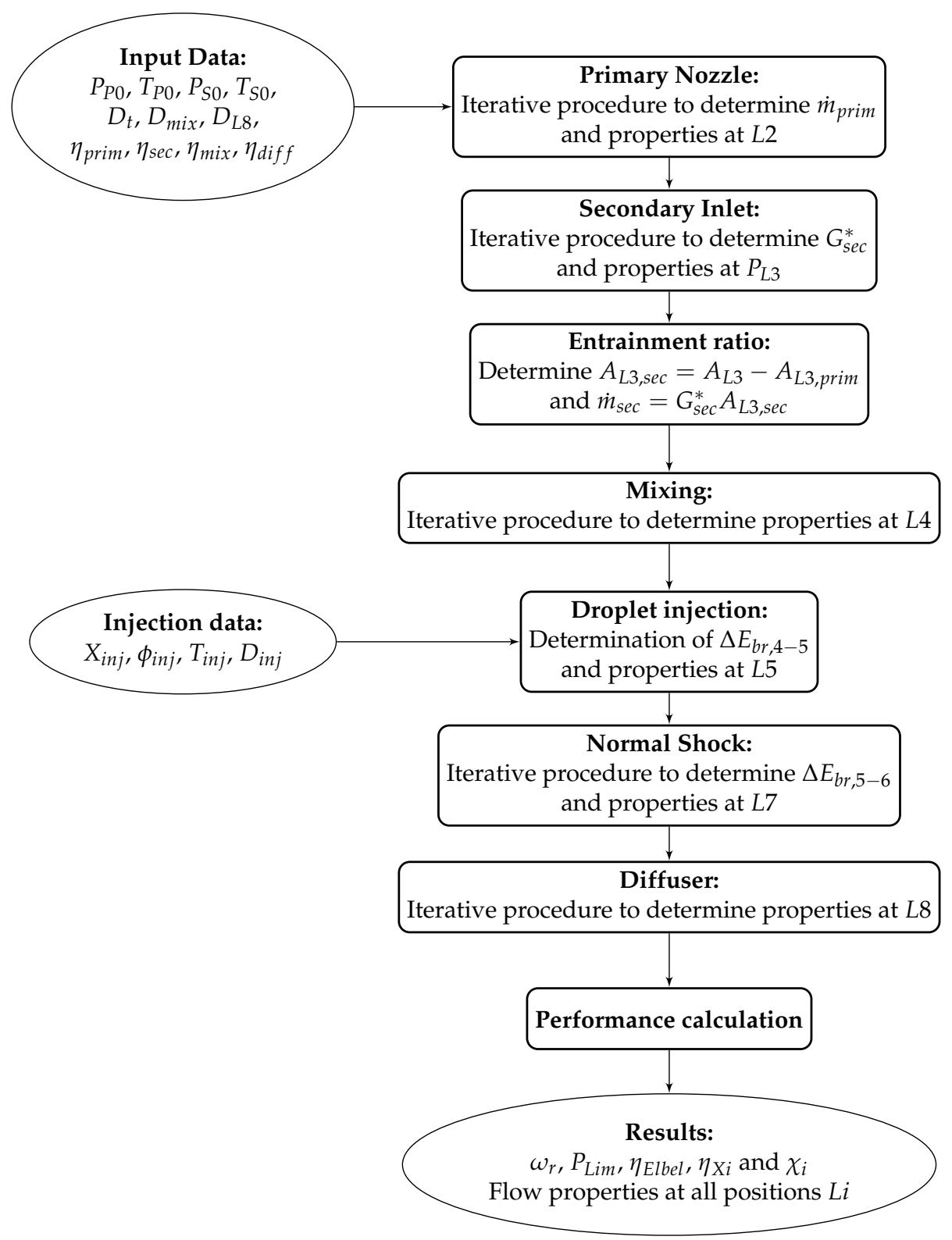

Figure 4. General calculation procedure of the thermodynamic model. Detailed steps for each region are given in Section 4.

\subsection{Motive Nozzle}

The motive nozzle flow rate is determined using the approach described in Section 2.2 for inlet properties $P_{P 0}$ and $T_{P 0}$ as follows:

1. Assume $P_{L 2}<P_{P 0}$.

2. Determine $h_{L 2}^{i s}=h_{L 2}^{i s}\left(P_{L 2}, s_{0}\right)$.

3. Using $\eta_{\text {prim }}$, correct $h_{\mathrm{L} 2}$ (Equation (7)) between the primary inlet and $L 2$.

4. Determine $\rho_{L 2}=\rho_{L 2}\left(P_{L 2}, h_{L 2}\right)$ and $V_{L 2}=\sqrt{0.5\left(h_{P 0}-h_{L 2}\right)}$.

5. Determine $G_{L 2}=\rho_{L 2} V_{L 2}$.

6. Repeat steps 2 through 5 reducing the guess $P_{L 2}$ value until $\max \left(G_{L 2}\right)$ is found.

7. $\quad \dot{m}_{\text {prim }}=\max \left(G_{L 2}\right) A_{L 2}$.

At the end of this step, the primary mass flow rate and the properties at the motive throat are determined. 


\subsection{Secondary Inlet}

The sonic conditions corresponding to $G_{s e c}^{*}$ are calculated using a procedure analogous to that described in Section 4.1 but using $P_{S 0}$ and $T_{S 0}$. By assuming that the secondary choking pressure is uniform across $L 3$ for both flows, the area occupied by the primary jet is calculated according to Equation (19):

$$
A_{L 3, \text { prim }}=\frac{\dot{m}_{\text {prim }}}{V_{L 3, \text { prim }} \rho_{L 3, \text { prim }}}=\frac{\dot{m}_{\text {prim }}}{\sqrt{\frac{1}{2}\left(h_{p o}-h_{L 3, \text { prim }}\right)} \rho_{L 3, \text { prim }}},
$$

where $h_{L 3, \text { prim }}$ is determined using $h_{P 0}, s_{P 0}$ and $\eta_{\text {prim }}$, and $\rho_{L 3, \text { prim }}$ is determined using $h_{L 3, \text { prim }}$ and $P_{L 3}$. The effective area, or minimal cross section available for the passage of the secondary flow, $A_{L 3, s e c}$, is:

$$
A_{L 3, \text { sec }}=A_{L 3}-A_{L 3, \text { prim }}
$$

Therefore, one gets:

$$
\dot{m}_{s e c}=G_{s e c}^{*} A_{L 3, s e c}
$$

\subsection{Mixing (L3-L4)}

The complete mixture of both inlet flows takes place between sections $L 3$ and $L 4$. Equations (3)-(5) are applied in this region to determine the mixture velocity $V_{L 4}$, pressure $P_{L 4}$ and enthalpy $h_{L 4}$ using the following steps:

1. Guess $V_{L 4}$.

2. Calculate $P_{L 4}$ (Equation (4)) and $h_{L 4}$ (Equation (5)).

3. Determine $\rho_{L 4}=\rho_{L 4}\left(P_{L 4}, h_{L 4}\right)$.

4. Calculate $V_{L 4}^{*}$ using Equation (3).

5. If $\left|V_{L 4}-V_{L 4}^{*}\right|>$ tolerance, substitute $V_{L 4}^{*} \rightarrow V_{L 4}$ and go back to step 1 . Else, the calculation is finished and flow properties at position $L 4$ are known.

\subsection{Droplet Injection (L4-L5)}

Droplets are injected before the onset of the normal shock wave. Given the high relative velocity between both phases, droplets breakup shortly after injection. By inserting the droplet related terms into the conservation balances between sections $L 4$ and $L 5$, the following system is obtained:

$$
\begin{gathered}
\rho_{L 4} V_{L 4} A_{L 4}+\dot{m}_{\text {droplets }}=\rho_{L 5} V_{L 5} A_{L 5}=\dot{m}_{5}, \\
{\left[P_{L 4} A_{L 4}\right]+\dot{m}_{L 4} V_{L 4}+\dot{m}_{\text {droplets }} V_{\text {droplets }}=\left[P_{L 5} A_{L 5}+\dot{m}_{L 5}\right],} \\
\dot{m}_{L 4}\left[h_{L 4}+\frac{1}{2} V_{L 4}^{2}\right]+\dot{m}_{\text {droplets }}\left[h_{\text {droplets }}+\frac{1}{2} V_{\text {droplets }}^{2}\right]=\dot{m}_{L 5}\left[h_{L 5}+\frac{1}{2} V_{L 5}^{2}\right]+\Delta E_{b r, 4-5} .
\end{gathered}
$$

It is assumed here that the droplet velocity $V_{\text {droplets }}$ is equal to the gas velocity just after breakup.

The simultaneous solution of Equations (22)-(24) gives the mixture properties just before the normal shock.

\subsection{Normal Shock (L5-L7)}

Between sections $L 5$ and $L 7$, it is assumed that a normal shock wave takes place, which creates a jump in the flow conditions $\left(P_{L 5}<P_{L 7}, s_{L 5}<s_{L 7}, \rho_{L 5}<\rho_{L 7}\right.$ and $\left.V_{L 5}>V_{L 7}\right)$ and induces a second breakup step. The cross sectional area is assumed to be constant between both locations, and equal to $A_{L 3}$. 
Using Equation( 3), the velocity $V_{L 7}$ can be eliminated from Equations (4) and (5), giving:

$$
\begin{gathered}
P_{L 6}=P_{L 5}+\rho_{L 5} V_{L 5}^{2}\left(1-\frac{\rho_{L 5}}{\rho_{L 7}}\right), \\
h_{L 7}=h_{L 5}+\frac{1}{2} V_{L 5}^{2}\left[1-\left(\frac{\rho_{L 5}}{\rho_{L 7}}\right)^{2}\right]-\frac{\Delta E_{b r, 5-6}}{\dot{m}_{5}} .
\end{gathered}
$$

The flow characteristics after the shock are determined as follows:

1. Guess $\rho_{L 7}>\rho_{L 5}$.

2. Calculate $P_{L 7}$ and $h_{L 7}$ using Equations (25) and (26), respectively.

3. Determine $\rho_{L 7}^{*}=\rho_{L 7}^{*}\left(P_{L 7}, h_{L 7}\right)$.

4. If $\left|\rho_{L 7}-\rho_{L 7}^{*}\right|>$ tolerance, substitute $\rho_{L 7}^{*} \rightarrow \rho_{L 7}$ and go back to step 1 . Else, the calculation is finished and flow properties at position $L 7$ are known.

\subsection{Diffuser (L7-L8)}

The ejector outlet pressure $P_{L 8}$ is determined using the conditions at $L 7$, the diffuser isentropic coefficient and the cross section at $L 8$. Since the area is constant between $L 6$ and $L 7$, it is assumed that changes in properties between both locations are negligible. The iterative procedure described below is applied to determine the flow properties at the ejector outlet:

1. Guess $V_{L 8}$.

2. Calculate $h_{L 8}^{i s}$ by applying Equation (5) between sections $L 7$ and $L 8$.

3. Determine $P_{L 8}=P_{L 8}\left(h_{L 8}^{i s}, s_{L 7}\right)$ and $\rho_{L 8}^{*}=\rho_{L 8}^{*}\left(P_{L 8}, s_{L 7}\right)$.

4. Calculate $\dot{m}_{L 8}^{x *}=\rho_{L 8}^{*} V_{L 8} A_{L 8}$.

5. If $\left|\dot{m}_{L 8}^{*}-\dot{m}_{L 7}\right|>$ tolerance, do $V_{L 8}=V_{L 8}+\Delta V_{L 8}$ and go back to step 1 .

6. Correct $h_{L 8}$ with $P_{L 8}$ and $\eta_{\text {diff }}$, and determine flow properties at $L 8$.

Once $h_{L 8}$ and $P_{L 8}$ are known, the rest of flow properties at $L 8$ can be determined. The resulting outlet pressure corresponds to the maximum compression ratio achievable by the ejector at given operating conditions [16].

\subsection{Ejector Performance Parameters}

Apart from $\omega_{r}$ and $P_{\text {ratio }}$, the ejector efficiency, the exergy efficiency and the exergy destruction index have been determined for better comparing the ejector performance at varying operating conditions and droplet injection characteristics.

\subsubsection{Ejector Efficiency}

The ejector efficiency proposed by Elbel and Hrnjak [11] compares the isentropic work required in the secondary flow compression to the work liberated through the isentropic expansion of the motive flow:

$$
\eta_{\text {Elbel }}=\omega_{r} \frac{h_{\text {out }}^{\text {is,sec }}-h_{\text {sec }}}{h_{\text {prim }}-h_{\text {out }}^{\text {is, prim }}},
$$

where $h_{\text {out }}^{i s, s e c}$ ( resp. $h_{\text {out }}^{\text {is,prim }}$ ) is the specific enthalpy at the ejector outlet following the isentropic secondary flow compression (resp. isentropic primary flow expansion) and $h_{\text {sec }}$ and $h_{\text {prim }}$ are, respectively, the specific enthalpies at the secondary and primary inlet. Note that the denominator in Equation (27) is the work difference existing between the isentropic and isenthalpic expansion of the motive flow. 


\subsubsection{Exergy Efficiency}

From the perspective of the 2nd Law of Thermodynamics, the exergy efficiency allows to analyze the performance of the ejector by comparing the output exergy flow rate of the ejector $\dot{\chi}_{\text {out }}$ to the total of the primary $\dot{\chi}_{\text {prim }}$ and secondary $\dot{\chi}_{\text {sec }}$ inlets:

$$
\eta_{\chi}=\frac{\dot{\chi}_{o u t}}{\dot{\chi}_{p r i m}+\dot{\chi}_{s e c}}
$$

with the exergy at the $i$-th boundary $\dot{\chi}_{i}$ coming from Equation (29):

$$
\dot{\chi}_{i}=\dot{m}_{i}\left[\left(h_{i}-h_{0}\right)-T_{0}\left(s_{i}-s_{0}\right)\right],
$$

where the subscript 0 denotes the reference or dead state. Given that the main purpose of the ejector is to provide exergy to the secondary flow, conditions at the secondary inlet are chosen for the dead state in all following calculations.

\subsubsection{Exergy Destruction Index}

The exergy destruction index $\xi_{i}$ compares the exergy destroyed within a specific region of the ejector $\dot{D}_{i}$ to the total exergy destroyed through the device $\dot{D}_{e j}[12]$ :

$$
\xi_{i}=\frac{\dot{D}_{i}}{\dot{D}_{e j}}=\frac{\dot{S}_{i, s t a r t}-\dot{S}_{i, e n d}}{\dot{S}_{\text {out }}-\dot{S}_{\text {prim }}-\dot{S}_{\text {sec }}}
$$

where $\dot{S}=\dot{m} s$ is the entropy flow rate at a boundary. $\xi_{i}$ allows for comparing the contribution to the total exergy destruction of each section.

\section{Validation of the Thermodynamic Model}

The model was validated against an extensive amount of published experimental data for various operating conditions and working fluids typical of single- and two-phase ejector based refrigeration cycles. Validation points for single-phase operation include: the entrainment ratio, limiting pressure and thermodynamical properties at different sections of the ejector. Concerning two-phase operation, comparisons were made regarding the choked mass flow through a convergent divergent nozzle and the effect of the primary inlet saturation on the entrainment ratio.

\subsection{Single-Phase Ejector}

Figure 5 compares the predicted entrainment ratio values against experimental data from different studies $[8,10,24,34-36]$ with varying dimensions, working gases and operating conditions. As a first step, friction and mixing losses are neglected here such that: $\eta_{\text {prim }}=\eta_{\text {sec }}=\eta_{\text {mix }}=\eta_{\text {diff }}=1$.

The majority of predicted values lie within $10 \%$ of the corresponding experimental point when $\omega_{r}$ is in the range $0.35-0.6$, which is a typical range for most ejector applications in refrigeration systems. Deviations beyond $20 \%$ are found at the lower range of $\omega_{r}$ values, often associated with high motive to outlet pressure ratios. No clear tendencies are found between the model deviation and the entrainment ratio or the working gas. 


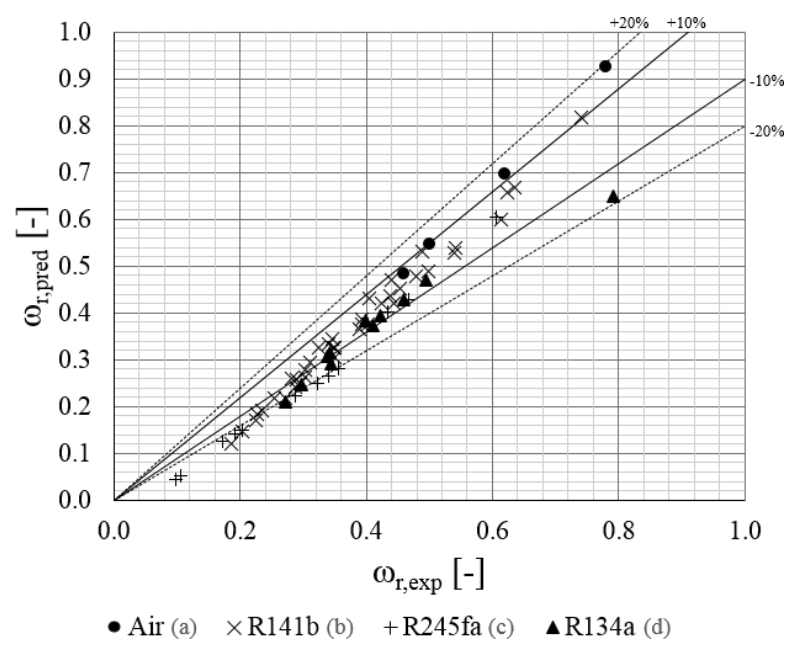

Figure 5. Comparison between the experimental and the predicted values of the entrainment ratio $\omega_{r}$ for different ejector configurations, under single-phase conditions, assuming 100\% efficiencies. Data sources: (a) [24,34], (b) [10], (c) Dr. Aidoun (CanmetEnergy, personal communication), (d) [8,35,36].

\section{Influence of the Loss Coefficients}

Figure 6 demonstrates the effect of the loss coefficients on the entrainment ratio $\omega_{r}$ and limiting pressure $P_{\text {lim }}$ for a constant area ejector with gaseous R134a as working fluid. Temperatures remain in the range $79-89^{\circ} \mathrm{C}$ and $5-10{ }^{\circ} \mathrm{C}$ for the primary and secondary inlets, respectively, and a $10^{\circ} \mathrm{C}$ superheat is applied to ensure vapor conditions [8]. The loss coefficients are shown in Table 1. These were determined in a CFD study using the same ejector and operating conditions by performing energy balances through the motive nozzle, secondary inlet, mixing section and diffuser [22]. Including losses in the thermodynamic model has a negligible effect on the predicted entrainment ratio, since it is only affected by the primary and secondary expansion coefficients, which are close to 1 in the present case. In terms of the limiting pressure, a better agreement is observed when using the adjusted loss coefficients $\eta_{\text {mix }}$ and $\eta_{\text {diff }}$, showing the greater influence of the mixing and diffusion processes on the ejector compressing capacity. Overall, the model determines $P_{\text {lim }}$ with an accuracy of $10 \%$.

The reader can refer to the works of Liu and Groll [37] and Liu [38] for detailed reviews about the influence of the loss coefficients on the performance of thermodynamic models.

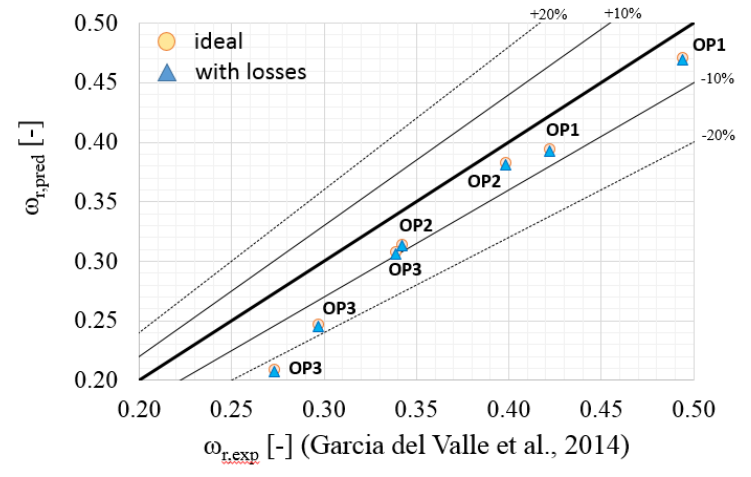

(a)

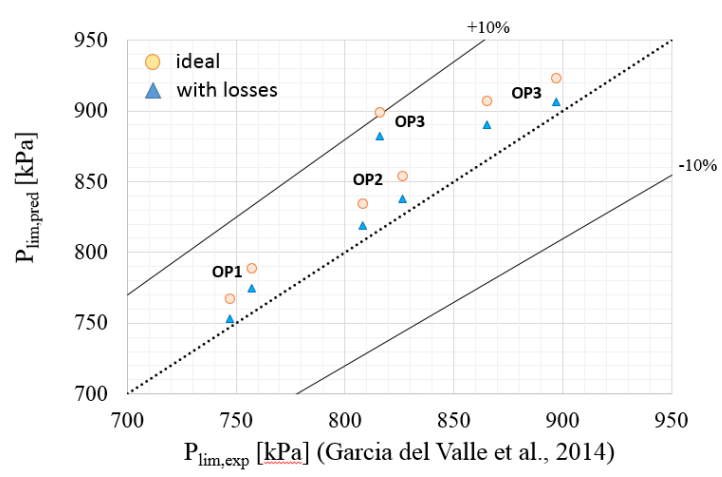

(b)

Figure 6. Comparison between the experimental and predicted values of (a) the entrainment ratio $\omega_{r}$ and (b) limiting pressure $P_{\text {lim }}$ for a single-phase R134a ejector. The operating conditions and loss coefficient values are shown in Table 1. Experimental data after [8]. 
Table 1. Values of the loss coefficients deduced from the CFD analysis of [22] for different operating conditions.

\begin{tabular}{cccccc}
\hline Operation Point & $\boldsymbol{P}_{\text {prim }}(\mathbf{k P a})$ & $\boldsymbol{T}_{\text {prim }}\left({ }^{\circ} \mathbf{C}\right)$ & $\eta_{\text {prim }}, \boldsymbol{\eta}_{\text {sec }}$ & $\boldsymbol{\eta}_{\text {mix }}$ & $\eta_{\text {diff }}$ \\
\hline OP1 & 2598.04 & 89.37 & 0.98 & 0.623 & 0.892 \\
OP2 & 2888.80 & 94.39 & 0.98 & 0.610 & 0.914 \\
OP3 & 3188.14 & 99.15 & 0.98 & 0.566 & 0.925 \\
\hline
\end{tabular}

\subsection{Comparisons at Different Sections of a Supersonic Ejector Working with R134a}

Table 2 shows a comparison between the thermodynamic model and CFD averaged values of pressure, temperature, Mach number $M a$, specific enthalpy and specific entropy at four locations along the ejector: L2, L4, L7 and L8. Operating conditions correspond to Operating Point OP2 of Table 1, with $T_{s e c}=20^{\circ} \mathrm{C}, P_{s e c}=414.6 \mathrm{kPa}$ and a fixed outlet pressure of $826.57 \mathrm{kPa}$. The CFD model is described in detail in Croquer et al. [39]. An average deviation of 3\% is achieved at the primary throat ( $L 2)$ and after mixing ( $L 4)$. The greatest differences are observed at the start of the diffuser $(L 7): 15 \%, 18.53 \%$ and $19.48 \%$ for $P, T$ and $M a$, respectively. These discrepancies may be partly explained by the $2 \mathrm{D}$ nature of the flow at this position highlighted by the CFD model [39]. In terms of global quantities, the primary and secondary mass flow rates according to the thermodynamic model (resp. CFD model) are $\dot{m}_{\text {prim }}=0.03753 \mathrm{~kg} / \mathrm{s}$ and $\dot{m}_{\text {sec }}=0.0143 \mathrm{~kg} / \mathrm{s}\left(\right.$ resp. $\dot{m}_{\text {prim }}=0.03747 \mathrm{~kg} / \mathrm{s}$ and $\left.\dot{m}_{\text {sec }}=0.0163 \mathrm{~kg} / \mathrm{s}\right)$, resulting in a difference of $0.15 \%$ and $14.3 \%$, respectively, for the primary and secondary flow rates between both models.

Table 2. Comparison with the CFD Model [39] at different ejector sections for OP2.

\begin{tabular}{ccccccc}
\hline Location & Model & $\boldsymbol{P}(\mathbf{k P a})$ & $\boldsymbol{T}\left({ }^{\circ} \mathbf{C}\right)$ & $\boldsymbol{M} \boldsymbol{a}(-)$ & $\boldsymbol{h}(\mathbf{J} / \mathbf{k g})$ & $\boldsymbol{s}(\mathbf{J} / \mathbf{k g} \cdot \mathbf{K}))$ \\
\hline \multirow{2}{*}{ L2 } & Therm. & 1807.42 & 70.55 & 0.99 & $437,616.82$ & 1730.67 \\
& CFD & 1697.38 & 67.55 & 1.05 & $436,267.09$ & 1730.51 \\
\hline \multirow{2}{*}{ L4 } & Therm. & 244.80 & 7.36 & 1.65 & $406,385.75$ & 1768.69 \\
& CFD & 264.10 & 7.60 & 1.58 & $406,096.63$ & 1761.80 \\
\hline \multirow{2}{*}{ L7 } & Therm. & 686.65 & 46.11 & 0.62 & $433,067.36$ & 1781.21 \\
& CFD & 596.92 & 38.90 & 0.77 & $427,724.66$ & 1774.34 \\
\hline \multirow{2}{*}{ L8 } & Therm. & 826.57 & 53.33 & 0.03 & $437,734.85$ & 1782.43 \\
& CFD & 826.57 & 52.25 & 0.03 & $436,640.63$ & 1779.08 \\
\hline
\end{tabular}

\subsection{Two-Phase Ejectors}

To assess the capability of the model in handling two-phase flows, the primary mass flow rate of $\mathrm{CO}_{2}$ through supersonic nozzles is compared with experimental values [40,41] at various inlet conditions indicated on the $P$ - $h$ diagram of Figure 7 . Results are presented in Figure 8 for different values of the primary nozzle efficiency $\eta_{\text {prim }}$, showing that the adjustment of $\eta_{\text {prim }}$ improves the model deviation from beyond $20 \%$ down to less than $10 \%$. The best agreement is obtained with $\eta_{\text {prim }}=0.75$ for the data in Figure $8 \mathrm{a}$ and with $\eta_{\text {prim }}=0.85$ for the data in Figure $8 \mathrm{~b}$.

The capacity of the present model to reproduce the effects of the primary superheat at the primary inlet $\left(\Delta_{\mathrm{OH}}=T_{\text {prim }}-T_{\text {prim }, \text { sat }}\right)$ on the entrainment ratio is shown in Figure 9 in comparison with the experimental values of Little and Garimella [25] for R134a. An average deviation of $4 \%$ is achieved. The linear dependency of $\omega_{r}$ with the superheat level is also well reproduced. For a $0{ }^{\circ} \mathrm{C}$ superheat, the calculated quality at the primary nozzle throat (resp. position L3) is 0.942 (resp. 0.933). 


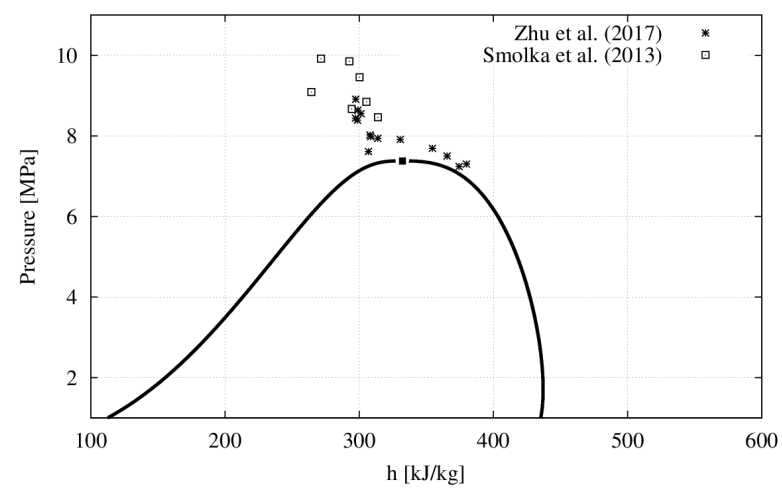

Figure 7. Location on a $P$ - $h$ diagram of the experimental inlet conditions used in the $\mathrm{CO}_{2}$ choked mass flow rate model validation. Data sources: [40,41].

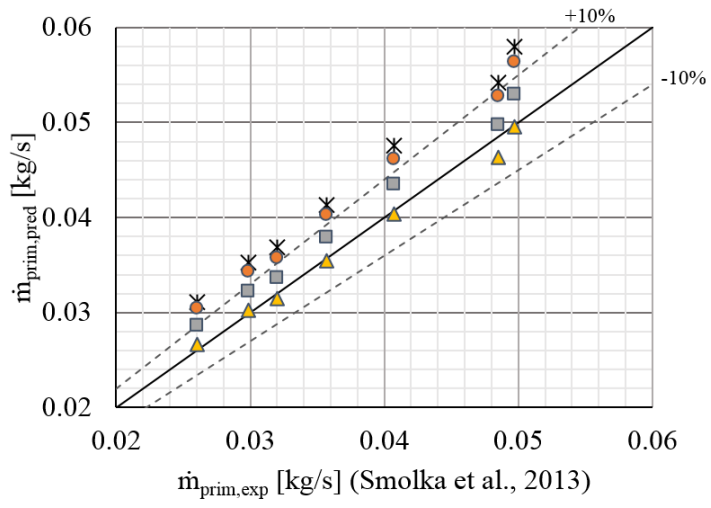

* Prim. Nozzle efficiency $=1 \quad 00.95 \square 0.85 \Delta 0.75$

(a)

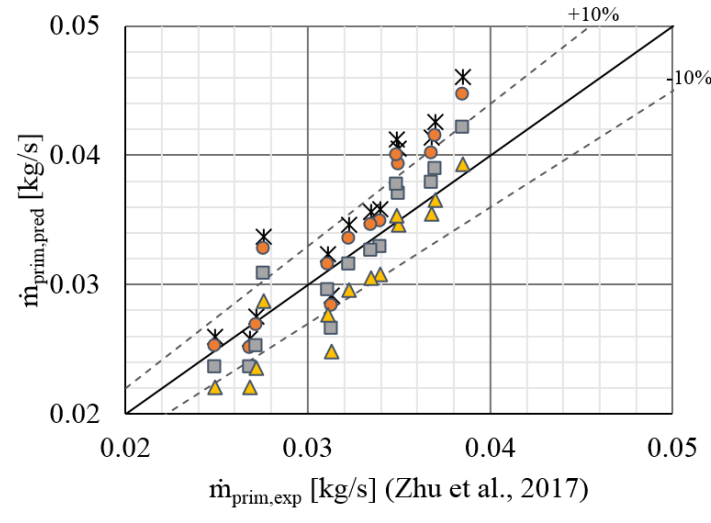

* Prim. Nozzle efficiency $=1 \quad 0.95 \square 0.85 \triangle 0.75$

(b)

Figure 8. Comparison between the experimental and predicted values of the primary mass flow rates for different ejector configurations under $\mathrm{CO}_{2}$ two-phase conditions. Data sources: $[40,41]$.

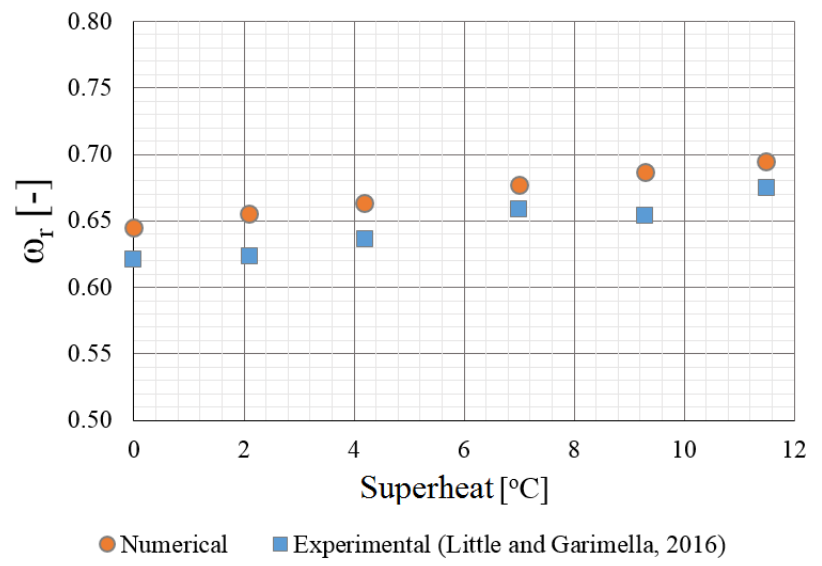

Figure 9. Comparison between the experimental and predicted values of the entrainment ratio $\omega_{r}$ for different superheat values. Experimental data after [25].

\section{Effect of Droplet Injection on the Ejector Performance}

The effect of droplet injection is assessed by modeling the case of a supersonic ejector with R134a as working fluid in the context of a HDRC. Primary inlet conditions are shown in Table 1 with $P_{\text {sec }}=414.6 \mathrm{kPa}$ and $T_{s e c}=20^{\circ} \mathrm{C}$. Four injection fraction values are considered: $X_{i n j}=1 \%, 2 \%, 5 \%$ and $10 \%$. For all 
cases, droplets of diameter $\phi_{i n j}=500 \mu \mathrm{m}$ (average value measured by Chauvin et al. [28] from a commercial atomizer) are injected at a temperature of $T_{i n j}=-13^{\circ} \mathrm{C}$ to ensure liquid phase at the typical CAS pressure values encountered. No variations are expected on the entrainment ratio due to the droplet injection at the CAS, since the model determines $\omega_{r}$ based solely on the inlet conditions and the throat areas $A_{L 2}$ and $A_{L 3, s e c}$ (see Section 2.2).

\subsection{Changes to Pressure and Mach Profiles}

The effect of droplet injection on pressure, Mach number $M a$ and temperature inside the ejector is shown in Figure 10, between sections $L 4$ (right before injection) and $L 8$ (diffuser outlet), for working conditions OP2 and injected droplet fractions between $1 \%$ and $10 \%$ of the primary mass flow rate without injection. To compute the Mach number, it is noticeable that the speed of sound is provided by the Coolprop library and not by any relation for two-phase flows.

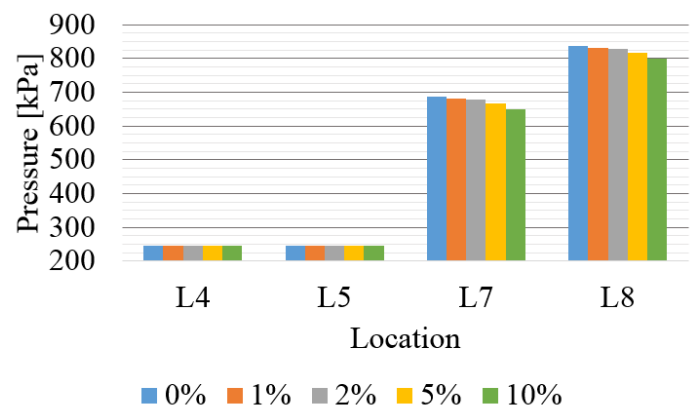

(a)

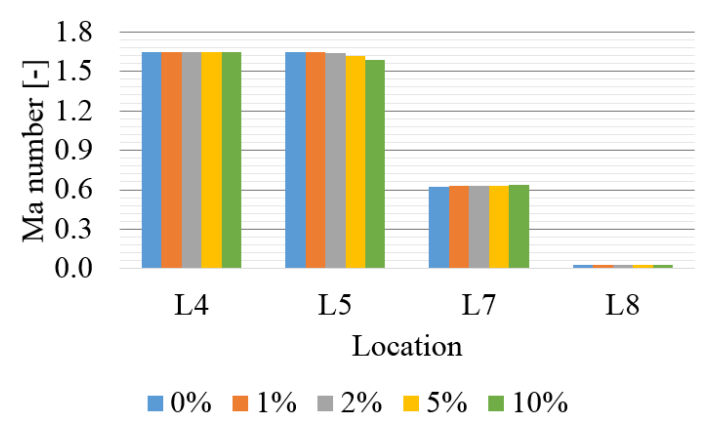

(b)

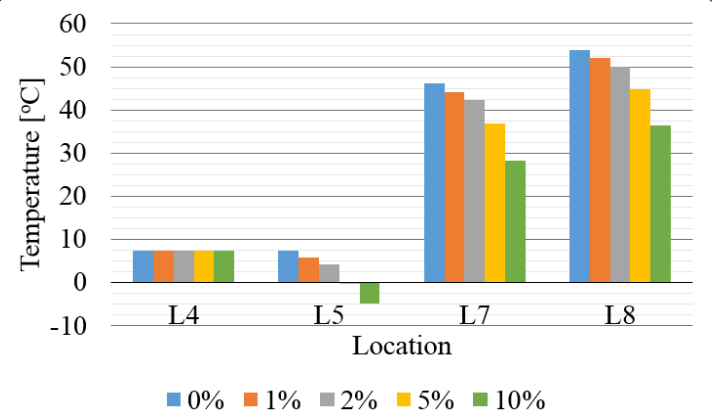

(c)

Figure 10. Effect of droplet injection fraction $X_{i n j}$ on the (a) pressure; (b) Mach number $M a$ and (c) temperature at different sections of the ejector. Results for R134a at the inlet conditions OP2 of Table 1.

Regarding the effect of droplet injection on pressure (Figure 10a), no changes are observed at sections $L 4$ and $L 5$, given the fact that the injection occurs in the CAS after full mixing of the primary and secondary flows. At position $L 7$, a pressure reduction is observed with increasing injection fraction, which suggests an effect on shock intensity. Moreover, the lower pressure at the start of the diffuser is carried on to the outlet conditions affecting the compression ratio. Concerning Ma values (Figure 10b), an increase in $X_{i n j}$ leads to lower $M a$ values at position L5. An opposite behavior is observed at position $L 7$, where the $M a$ number slightly increases with $X_{i n j}$. At the diffuser outlet, the $M a$ number is $\sim 0.03$ for all cases. These $M a$ profiles reflect that the flow in general decelerates with the injection of droplets, although the changes are barely noticeable. The most drastic impact of droplet injection is observed in the temperature profiles (Figure 10c). For an injected fraction of $10 \%$, the temperature after injection reduces by $12{ }^{\circ} \mathrm{C}$, and the across-shock temperature jump reduces by $60 \%$ in comparison with the case $X_{i n j}=0$. A similar temperature reduction is observed at the outlet. The saturation temperature at $L 8$ remains close to $33^{\circ} \mathrm{C}$ for all the assessed conditions, meaning that increasing 
droplet injection reduced the superheat at the outlet from $20^{\circ} \mathrm{C}$ to $5^{\circ} \mathrm{C}$. This behavior was identical for working conditions OP1 and OP3.

\subsection{Shock Intensity}

The intensity of the shock wave towards the end of the CAS is assessed in terms of the pressure $\Delta P$ and Mach number $\Delta M a$ jumps between sections $L 5$ and L7. Figure 11 shows the effect of the droplet injection on these quantities for the conditions OP2. The pressure increase has been normalized by the value obtained in the case without any injection, $\Delta P_{o}$. Both quantities, $\Delta P$ and $\Delta M a$, decrease proportionally with the injected mass fraction. At the maximum injection fraction considered ( $X_{i n j}=10 \%$ ) a reduction of $\sim 8 \%$ is observed for both quantities.

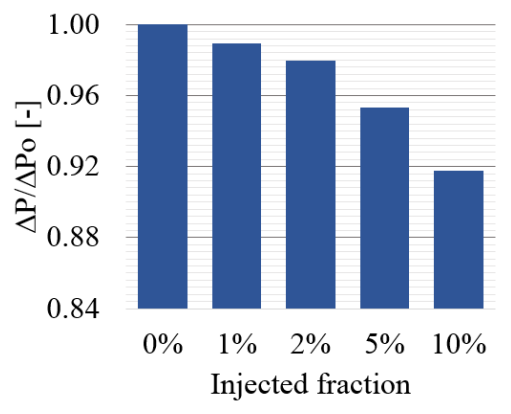

(a)

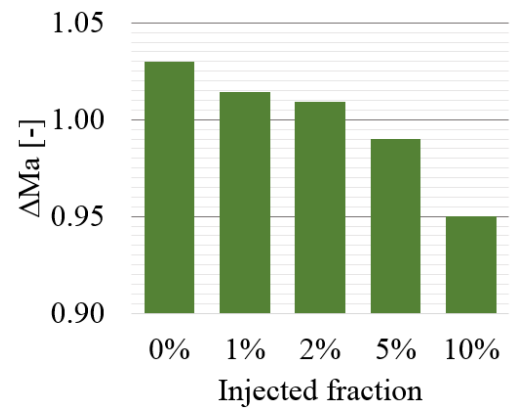

(b)

Figure 11. Effect of the droplet injection fraction $X_{i n j}$ on the (a) pressure and (b) Mach number $M a$ change across the shock wave, relative to the case without droplets. Results for R134a at the inlet conditions OP2 of Table 1.

These results show that the injection of droplets effectively attenuates the shock wave intensity in the CAS, thus affecting one of the main sources of irreversibilities inside the ejector [12,22]. At the maximum injected fraction considered, the entropy generation between sections $L 5$ and $L 7$ is reduced by $10 \%$ relative to the case without injection.

\subsection{Limiting Pressure}

The effect of the droplet injection fraction $X_{i n j}$ on the limiting pressure for the three operating conditions OP1, OP2 and OP3 is shown in Figure 12. The limiting compression ratio diminishes proportionally with the increasing injection fraction, from $1 \%$ at $X_{i n j}=1 \%$ to $5 \%$ at $X_{i n j}=10 \%$. This reduction in the outlet pressure is related to the lower pressure observed at the diffuser inlet with increased injection fraction (Figure 10a). It is important to point out that, although this behavior was assessed for fixed secondary inlet conditions, there is no reason to believe the tendency would be any different when varying the conditions of the entrained flow.

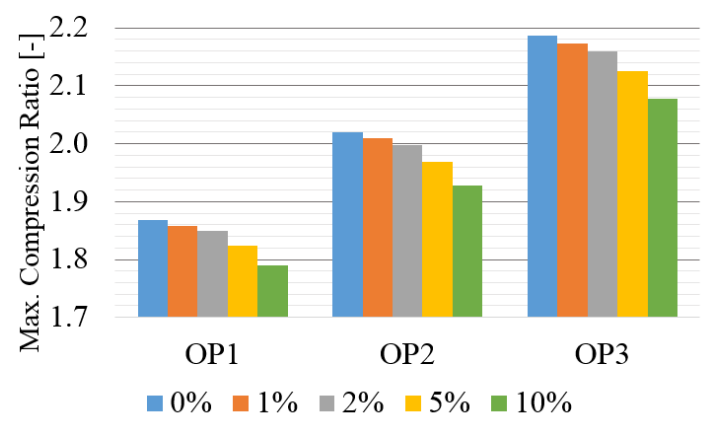

Figure 12. Effect of the droplet injection fraction $X_{i n j}$ on the maximum compression ratio achievable by the ejector. Results for R134a at the inlet conditions OP1, OP2 and OP3 of Table 1. 


\subsection{Ejector Efficiency and Exergy Performance}

Figure 13 shows the variations in the ejector efficiency and exergy efficiency with injection fractions of $1 \%$ to $10 \%$ at the conditions OP1, OP2 and OP3 and for $P_{s e c}=414.6 \mathrm{kPa}$ and $T_{\text {sec }}=20^{\circ} \mathrm{C}$. Both the exergy efficiency and the ejector efficiency reduce with increasing $X_{i n j}$, independently of the operating conditions. Regarding $\eta_{E l b e l}$, an average performance loss of $11 \%$ is observed for the greatest injection fraction, reflecting the decrease in the outlet pressure shown in Figure 10. For lower outlet pressures at fixed inlet conditions, the secondary flow compression ratio diminishes while the primary flow expands even more, resulting in less energy recovered by the ejector.
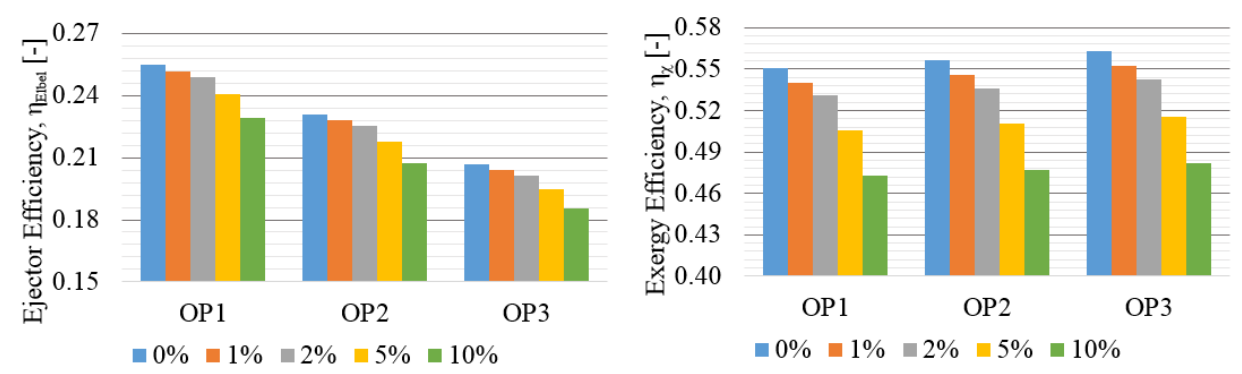

Figure 13. Effect of the droplet injection fraction $X_{i n j}$ on the ejector efficiency $\eta_{E l b e l}$ and exergy efficiency $\eta_{\chi}$. Results for R134a at the inlet conditions OP1, OP2 and OP3 of Table 1.

Concerning the exergy efficiency, a reduction of $15 \%$ in average is observed when the injection mass fraction is $10 \%$, confirming that droplet injection results in less exergy recovered relative to the total entering at both inlets. The location where this exergy is destroyed can be pinpointed using the exergy destruction index as shown in Figure 14. Although droplets effectively attenuate the normal shocks in the CAS and reduce their contribution to exergy destruction by about $35 \%$ for $X_{i n j}=10 \%$, other processes associated with the droplet injection (e.g., mixing with the main flow) present an even greater contribution to the total exergy destroyed. For example, in the limiting case of $X_{i n j}=10 \%, 3.9 \mathrm{~kJ} / \mathrm{kg}$ of exergy are destroyed at the point of injection, which is six times the exergy destroyed across the shock wave in the case without injection. Thus, although the expected shock attenuation effect is carried out, other factors damaging the effectiveness of the ejector are introduced, resulting in a lower performance. From the perspective of a HDRC, a lower performance would be expected given that the injection of droplets renders the ejector less effective for energy recovery and compression.

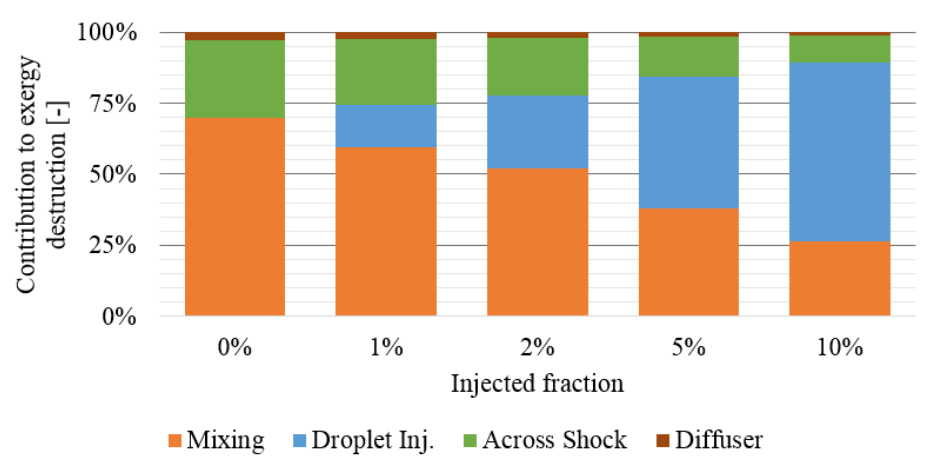

Figure 14. Effect of the droplet injection fraction $X_{i n j}$ on the contribution of each section to the exergy destruction across the ejector. Results for R134a at the inlet conditions OP2 of Table 1.

\section{Conclusions}

In this paper, a thermodynamic model has been developed to predict the entrainment ratio and compression ratio of supersonic gas ejectors with droplets for HDRC applications, given the 
inlet operating conditions and key geometry parameters (primary throat, mixing section and diffuser outlet diameter). It has been extensively validated against published experimental or numerical data for single- and two-phase flows. The model has then been extended to assess the effect of injecting droplets at the constant area section of the device over different performance parameters: ejector efficiency, exergy destruction and maximum compression ratio. The following conclusions can be drawn:

- Under single-phase conditions and fixing all losses coefficients to 1 , the model determines the entrainment ratio with an average deviation of $18 \%$ for various working fluids (Air, R141b, R245fa and R134a) and the double-choke limiting pressure for R134a with a mean accuracy of $4.5 \%$. The inclusion of adjusted losses coefficients has a negligible effect on the determined entrainment ratio but reduces the deviation in $P_{l i m}$ to $2.5 \%$.

- Under two-phase conditions, the model presents a deviation of about $10 \%$ in the choked mass flow of $\mathrm{CO}_{2}$ across a convergent-divergent nozzle. In this case, the use of loss coefficients greatly improves the results. The effect of the primary inlet superheat over the entrainment ratio is also accurately reproduced.

- An analysis of a R134a ejector under typical operating conditions of a HDRC shows that the injection of droplets results in a lower ejector performance. Although at an injection fraction of $10 \%$, the shock intensity reduces by $8 \%$, the ejector efficiency and exergy efficiency reduce by $11 \%$ and $15 \%$, respectively. Exergy destruction profiles show that the gains achieved by the shock attenuation are overcome by the entropy generated by the droplet injection and its mixing with the main flow.

Acknowledgments: This project is part of the research program of the NSERC (The Natural Sciences and Engineering Research Council of Canada) Chair on Industrial Energy Efficiency, established at Université de Sherbrooke in 2014, with the support of Hydro-Québec, Ressources Naturelles Canada (CanmetEnergy in Varennes), Rio Tinto Alcan, and the Natural Sciences and Engineering Research Council of Canada.

Author Contributions: Sergio Croquer conceived the thermodynamic model and performed all calculations, and all authors analyzed the data and contributed to the writing of the paper. All authors have read and approved the final manuscript.

Conflicts of Interest: The authors declare no conflict of interest.

\section{Abbreviations}

The following abbreviations are used in this manuscript:

CAS Constant Area Section

CFD Computational Fluid Dynamics

COP Coefficient of Performance

HDRC Heat Driven Refrigeration Cycle

OP Operating Point

\section{References}

1. Sumeru, K.; Nasution, H.; Ani, F. A review on two-phase ejector as an expansion device in vapor compression refrigeration cycle. Renew. Sustain. Energy Rev. 2012, 16, 4927-4937.

2. Chen, J.; Jarall, S.; Havtun, H.; Palm, B. A review on versatile ejector applications in refrigeration systems. Renew. Sustain. Energy Rev. 2015, 49, 67-90.

3. Besagni, G.; Mereu, R.; Inzoli, F. Ejector refrigeration: A comprehensive review. Renew. Sustain. Energy Rev. 2016, 53, 373-407.

4. Fang, Y.; Croquer, S.; Poncet, S.; Aidoun, Z.; Bartosiewicz, Y. Drop-in replacement in a R134 ejector refrigeration cycle by HFO refrigerants. Int. J. Refrig. 2017, 77, 87-98.

5. Thongtip, T.; Ruangtrakoon, N.; Aphornratana, S. Development of a Steam Jet Refrigeration Cycle for the Actual Application Driven by Low Grade Thermal Energy. Energy Procedia 2014, 52, 110-119.

6. Meyer, A.; Harms, T.; Dobson, R. Steam jet ejector cooling powered by waste or solar heat. Renew. Energy 2009, 34, 297-306. 
7. Zegenhagen, T.; Ziegler, F. Experimental investigation of the characteristics of a jet-ejector and a jet-ejector cooling system operating with R134a as a refrigerant. Int. J. Refrig. 2015, 56, 173-185.

8. García del Valle, J.; Saíz Jabardo, J.; Castro Ruiz, F.; San José Alonso, J. An experimental investigation of a R134a ejector refrigeration system. Int. J. Refrig. 2014, 46, 105-113.

9. Chunnanond, K.; Aphornratana, S. Ejectors: Applications in refrigeration technology. Renew. Sustain. Energy Rev. 2004, 8, 129-155.

10. Huang, B.; Chang, J.; Wang, C.; Petrenko, V. A 1-D analysis of ejector performance. Int. J. Refrig. 1999, 22, 354-364.

11. Elbel, S.; Hrnjak, P. Experimental validation of a prototype ejector designed to reduce throttling losses encountered in transcritical R744 system operation. Int. J. Refrig. 2008, 31, 411-422.

12. Bilir Sag, N.; Ersoy, H.; Hepbasli, A.; Halkaci, H. Energetic and exergetic comparison of basic and ejector expander refrigeration systems operating under the same external conditions and cooling capacities. Energy Convers. Manag. 2015, 90, 184-194.

13. Lawrence, N.; Elbel, S. Analysis of two-phase ejector performance metrics and comparison of R134a and $\mathrm{CO}_{2}$ ejector performance. Sci. Technol. Built Environ. 2015, 21, 515-525.

14. Munday, J.; Bagster, D. A new ejector theory applied to steam jet refrigeration. Ind. Eng. Chem. Process Des. Dev. 1977, 16, 442-449.

15. Chen, W.; Liu, M.; Chong, D.T.; Yan, J.; Little, A.; Bartosiewicz, Y. A 1D model to predict ejector performance at critical and sub-critical operational regimes. Int. J. Refrig. 2013, 36, 1750-1761.

16. Galanis, N.; Sorin, M. Ejector design and performance prediction. Int. J. Therm. Sci. 2016, 104, 315-329.

17. García del Valle, J.; Sáiz Jabardo, J.; Castro Ruiz, F.; San José Alonso, J. A one-dimensional model for the determination of an ejector entrainment ratio. Int. J. Refrig. 2012, 35, 772-784.

18. Maytal, B.Z.; Elias, E. Two-phase choking conditions of real gases flow at their critical stagnation temperatures and closely above. Cryogenics 2009, 49, 469-481.

19. Palacz, M.; Smolka, J.; Fic, A.; Bulinski, Z.; Nowak, A.J.; Banasiak, K.; Hafner, A. Application range of the HEM approach for $\mathrm{CO}_{2}$ expansion inside two-phase ejectors for supermarket refrigeration systems. Int. J. Refrig. 2015, 59, 251-258.

20. Ameur, K.; Aidoun, Z.; Ouzzane, M. Modeling and numerical approach for the design and operation of two-phase ejectors. Appl. Therm. Eng. 2016, 109, 809-818.

21. He, S.; Li, Y.; Wang, R. Progress of mathematical modeling on ejectors. Renew. Sustain. Energy Rev. 2009, 13, 1760-1780.

22. Croquer, S.; Poncet, S.; Aidoun, Z. Turbulence modeling of a single-phase R134a supersonic ejector. Part 2: Local flow structure and exergy analysis. Int. J. Refrig. 2016, 61, 153-165.

23. Al-Ansary, H.; Jeter, S. Numerical and Experimental Analysis of Single-Phase and Two-Phase Flow in Ejectors. HVACER Res. 2004, 10, 521-538.

24. Hemidi, A.; Henry, F.; Leclaire, S.; Seynhaeve, J.M.; Bartosiewicz, Y. CFD analysis of a supersonic air ejector. Part I: Experimental validation of single-phase and two-phase operation. Appl. Therm. Eng. 2009, 29, 1523-1531.

25. Little, A.; Garimella, S. Shadowgraph visualization of condensing R134a flow through ejectors. Int. J. Refrig. 2016, 68, 118-129.

26. Igra, O.; Falcovitz, J.; Houas, L.; Jourdan, G. Review of methods to attenuate shock/blast waves. Prog. Aerosp. Sci. 2013, 58, 1-35.

27. Jourdan, G.; Biamino, L.; Mariani, C.; Blanchot, C.; Daniel, E.; Massoni, J.; Houas, L.; Tosello, R.; Praguine, D. Attenuation of a shock wave passing through a cloud of water droplets. Shock Waves 2010, 20, 285-296.

28. Chauvin, A.; Jourdan, G.; Daniel, E.; Houas, L.; Tosello, R. Experimental investigation of the propagation of a planar shock wave through a two-phase gas-liquid medium. Phys. Fluids 2011, 23, 1-14.

29. Bell, I.H.; Wronski, J.; Quoilin, S.; Lemort, V. Pure and Pseudo-pure Fluid Thermophysical Property Evaluation and the Open-Source Thermophysical Property Library CoolProp. Ind. Eng. Chem. Res. 2014, 53, 2498-2508.

30. Maytal, B.Z. Real gas choked flow conditions at low reduced-temperatures. Cryogenics 2006, 46, 21-29.

31. Adiga, K.; Willauer, H.D.; Ananth, R.; Williams, F.W. Implications of droplet breakup and formation of ultra fine mist in blast mitigation. Fire Saf. J. 2009, 44, 363-369.

32. Pilch, M.; Erdman, C. Use of breakup time data and velocity history data to predict the maximum size of stable fragments for acceleration-induced breakup of a liquid drop. Int. J. Multiph. Flow 1987, 13, 741-757. 
33. Liao, Y.; Lucas, D. A literature review of theoretical models for drop and bubble breakup in turbulent dispersions. Chem. Eng. Sci. 2009, 64, 3389-3406.

34. Chong, D.; Hu, M.; Chen, W.; Wang, J.; Liu, J.; Yan, J. Experimental and numerical analysis of supersonic air ejector. Appl. Energy 2014, 130, 679-684.

35. Ersoy, H.K.; Bilir Sag, N. Preliminary experimental results on the R134a refrigeration system using a two-phase ejector as an expander. Int. J. Refrig. 2014, 43, 97-110.

36. Hakkaki-fard, A.; Poirier, M.; Aidoun, Z.; Ouzzane, M.; Guiguere, D. An experimental study of an ejector supported by CFD. In Proceedings of the 24th International Congress of Refrigeration, Yokohama, Japan, 16-22 August 2015; pp. 1-8.

37. Liu, F.; Groll, E. Study of ejector efficiencies in refrigeration cycles. Appl. Therm. Eng. 2013, 52, 360-370.

38. Liu, F. Review on Ejector Efficiencies in Various Ejector Systems. In Proceedings of the International Refrigeration and Air Conditioning Conference, West Lafayette, IN, USA, 14-17 July, 2014.

39. Croquer, S.; Poncet, S.; Aidoun, Z. Turbulence modeling of a single-phase R134a supersonic ejector. Part 1: Numerical benchmark. Int. J. Refrig. 2016, 61, 140-152.

40. Smolka, J.; Bulinski, Z.; Fic, A.; Nowak, A.J.; Banasiak, K.; Hafner, A. A computational model of a transcritical R744 ejector based on a homogeneous real fluid approach. Appl. Math. Model. 2013, 37, 1208-1224.

41. Zhu, Y.; Wang, Z.; Yang, Y.; Jiang, P. Flow visualization of supersonic two-phase transcritical flow of $\mathrm{CO}_{2}$ in an ejector of a refrigeration system. Int. J. Refrig. 2017, 74, 352-359.

(c) 2017 by the authors. Licensee MDPI, Basel, Switzerland. This article is an open access article distributed under the terms and conditions of the Creative Commons Attribution (CC BY) license (http://creativecommons.org/licenses/by/4.0/). 